\title{
Three-Dimensional Bioelectrodes Utilizing Graphene Based Bioink
}

Werchmeister, Rebecka Maria Larsen; Tang, Jing; Xiao, Xinxin; Wollenberger, Ulla; Hjuler, Hans Aage; Ulstrup, Jens; Zhang, Jingdong

Published in:

Journal of The Electrochemical Society

Link to article, DOI:

10.1149/2.0261916jes

Publication date:

2019

Document Version

Peer reviewed version

Link back to DTU Orbit

Citation (APA):

Werchmeister, R. M. L., Tang, J., Xiao, X., Wollenberger, U., Hjuler, H. A., Ulstrup, J., \& Zhang, J. (2019).

Three-Dimensional Bioelectrodes Utilizing Graphene Based Bioink. Journal of The Electrochemical Society, 166(16), G170-G177. https://doi.org/10.1149/2.0261916jes

\section{General rights}

Copyright and moral rights for the publications made accessible in the public portal are retained by the authors and/or other copyright owners and it is a condition of accessing publications that users recognise and abide by the legal requirements associated with these rights.

- Users may download and print one copy of any publication from the public portal for the purpose of private study or research.

- You may not further distribute the material or use it for any profit-making activity or commercial gain

- You may freely distribute the URL identifying the publication in the public portal 


\section{Post-printed version}

To cite this paper: Rebecka Maria Larsen Werchmeister, Jing Tang, Xinxin Xiao, Ulla Wollenberger, Hans Aage Hjuler, Jens Ulstrup, Jingdong Zhang; Three-Dimensional Bioelectrodes Utilizing Graphene Based Bioink, Journal of The Electrochemical Society 2019, 166 (16) G170-G177

\section{Three-dimensional bioelectrodes utilizing graphene based bioink}

Rebecka Maria Larsen Werchmeister ${ }^{1,}$, Jing Tang ${ }^{1, \text { a }}$, Xinxin Xiao ${ }^{1}$, Ulla Wollenberger ${ }^{2}$, Hans Aage Hjuler $^{3}$, Jens Ulstrup ${ }^{1,4}$, Jingdong Zhang ${ }^{1, *}$

${ }^{1}$ Department of Chemistry, Technical University of Denmark, Kongens Lyngby 2800, Denmark

${ }^{2}$ Department of Analytical Biochemistry, University of Potsdam, Potsdam-Golm, 14476, Germany

${ }^{3}$ Danish Power Systems ApS, Egeskovvej 6C, DK-3490 Kvistgård, Denmark

${ }^{4}$ Kazan National Research Technological University, K. Marx Str., 68, 420015 Kazan, Republic of Tatarstan, Russian Federation

*jz@kemi.dtu.dk

${ }^{a}$ R. M. L. Werchmeister and J. Tang contributed equally to the present work. 


\begin{abstract}
Enzyme immobilization using nanomaterials offers new approaches to enhanced bioelectrochemical performance and is essential for the preparation of bioelectrodes with high reproducibility and low cost. In this report, we describe the development of new three-dimensional (3D) bioelectrodes by immobilizing a "bioink" of glucose oxidase (GOD) in a matrix of reduced graphene oxides (RGOs), polyethylenimine (PEI), and ferrocene carboxylic acid $(\mathrm{FcCOOH})$ on carbon paper (CP). CP with 3D interwoven carbon fibers serves as a solid porous and electronically conducting skeleton, providing large surface areas and space for loading the bioink and diffusion of substrate molecules. RGO enhances contact between the GOD-matrix and CP, maintaining high conductivity. The composition of the bioink has been systematically optimized. The GOD bioelectrodes show linearly increasing electrocatalytic oxidation current towards glucose concentration up to $48 \mathrm{mM}$. A hybrid enzymatic biofuel cell equipped with the GOD bioelectrode as a bioanode and a platinum cathode furthermore registers a maximum power density of $5.1 \mu \mathrm{W} \mathrm{cm}{ }^{-2}$ and an open circuit voltage of $0.40 \mathrm{~V}$ at $25{ }^{\circ} \mathrm{C}$. The new method reported of preparing a bioelectrode by drop-casting the bioink onto the substrate electrode is facile and versatile, with the potential of application also for other enzymatic bioelectrodes.
\end{abstract}

Keywords: bioink, 3D bioelectrodes, enzymatic biofuel cell, glucose oxidase, graphene oxide 


\section{Introduction}

Redox enzymes with high efficiency and selectivity have been widely studied as sustainable electrocatalysts in bioelectrochemistry. ${ }^{1-3}$ The immobilization of the redox enzyme on a solid electrode, allowing strong interfacial electric communication is a key process for the development of biosensors and biofuel cells. ${ }^{4-6}$ Enzyme immobilization is also important in implantable and reuseable bioelectrochemical devices such as biosensors ${ }^{7}$ and enzymatic biofuel cells (EBFCs). ${ }^{8-9}$

The main methods of immobilizing enzymes onto electrodes include adsorption, covalent binding and entrapment/encapsulation. Adsorption is a mild process of enzyme deposition on the electrode surface via weak interactions such as van der Waals or electrostatic interactions. ${ }^{10-11}$ Although covalent binding can anchor the proteins tightly on the electrode surfaces, for instance via amide bonding between the amino-acid residues of the enzyme and the electrode surface, covalent bonding sometimes involves harsh chemistry, resulting in enzyme denaturation. ${ }^{12-13}$ Entrapping or encapsulating enzyme within a polymeric matrix has recently become attractive due to facile operation and only a slight decrease in enzyme activity after immobilization. ${ }^{12}$

Introducing nanomaterials in the bioelectrode fabrication offers new approaches to enhance the stability and catalytic efficiency of the immobilized enzyme. ${ }^{14-15}$ This requires, however, altering established routes for the enzyme immobilization. Various conductive nanoparticles ${ }^{16-17}$ or carbon nanomaterials ${ }^{18-19}$ have been developed and used to promote bioelectrochemical ET. In our earlier work, gold nanoparticles were used to enhance the bioelectrocatalytic dioxygen reduction at a bilirubin oxidase (BOD) modified biocathode. ${ }^{20}$ It has been reported that carbon nanotubes (CNTs) and nanospheres show more than $80 \%$ activity retention. ${ }^{21-22}$ Due to its excellent lateral electronic conductivity, superior mechanical strength, and high surface area, ${ }^{23}$ graphene has been used as bioelectrode material in biosensors and biofuel cells. ${ }^{24-25}$ Graphene can be produced by reduction of graphite derived graphene oxide (GO), resulting in reduced graphene oxide (RGO) with unique biocompatibility due to the presence of residual surface hydroxyl and carbonyl groups. To enable a wide application of bioelectrodes in implanted or flexible electronic devices, three-dimensional (3D) or free-standing graphene based electrodes, such as graphene foam, ${ }^{26-27}$ crumbled graphene, ${ }^{28}$ and graphene paper ${ }^{29-31}$ have emerged recently as promising electrode candidates. Among these, graphene papers with high flexibility and conductivity have been utilized to immobilize enzymes such as glucose dehydrogenase and BOD. ${ }^{30-31}$ Very recently, our group reported a 3D graphene sulfite oxidase (SO) bioelectrode using RGO coated carbon papers (CPs). The rational design of the 
electrode surface introducing polycation polyethylenimine (PEI) enabled favorable orientation of SO via electrostatic binding, leading to facile direct electron transfer (DET). ${ }^{32}$

Due to its high enzyme activity, selectivity, and low cost, glucose oxidase (GOD) from Aspergillus niger, is a widely used enzyme for biosensors and biofuel cells for the determination of blood sugar and electricity harvesters, respectively. GOD is a dimeric enzyme with a molecular mass of 130 to $175 \mathrm{kDa}$ depending on origin and glycosylation level. ${ }^{33}$ The dimeric unit contains one flavin adenine dinucleotide (FAD) redox center as a cofactor, deeply buried (around 13-17 $\AA$ ) inside the enzyme. ${ }^{34-}$ ${ }^{35}$ DET channels from the enzyme to the electrode are virtually blocked, and mediated ET (MET) therefore applied instead. A small mediator redox molecule shuttles the electrons between FAD and the electrode surface. Ferrocene is one of the most frequently used mediators in GOD bioelectrodes due to its favorable physicochemical properties, high interfacial ET rates in particular. ${ }^{36}$ Use of ferrocene as a mediator of GOD was first reported in $1984 .{ }^{37}$ In later work ferrocene was covalently attached onto linear polymers for used in several promising biosensors and biofuel cells, ${ }^{38-41}$ but synthesis of such redox polymers is time and labor demanding. Finding a versatile and facile biomatrix on the electrode for enzyme immobilization is therefore of significant interest.

In the present work, we aim at developing a new facile and general route for construction of 3D bioelectrodes. The fabricated 3D bioelectrodes are built up by simply drop-casting a novel type GODgraphene "bioink" onto porous carbon paper electrodes, Scheme 1. Carbon paper made of micro carbon fibers and organized in three dimensions, serves as a microporous skeleton with high mechanical strength and good conductivity. The bioink consists of a mediator together with GOD and graphene. Graphene provides a large surface area for GOD loading as well as high electronic conductivity among the components of the bioink. The mediator is introduced by immobilizing the negatively charged ferrocene carboxylic acid $(\mathrm{FcCOOH})$ electrostatically onto positively charged PEI. PEI is a polymer with many amine groups (isoelectric point above 10), ${ }^{42}$ and interacts strongly both with negatively charged proteins and (deprotonated) $\mathrm{FcCOOH}$ through electrostatic forces. ${ }^{43} \mathrm{~A}$ thin layer of Nafion is applied on the top of the dried bioelectrode to avoid leakage of the enzyme. We furthermore optimized systematically the composition of the bioink and working media. Graphene obtained by reducing GO enhances the electronic conductivity between the ink components and the electrode surface, giving a high catalytic response. The optimized bioelectrodes display a wide linear range for glucose sensing. The electrodes can furthermore be used as bioanodes in EBFCs. 


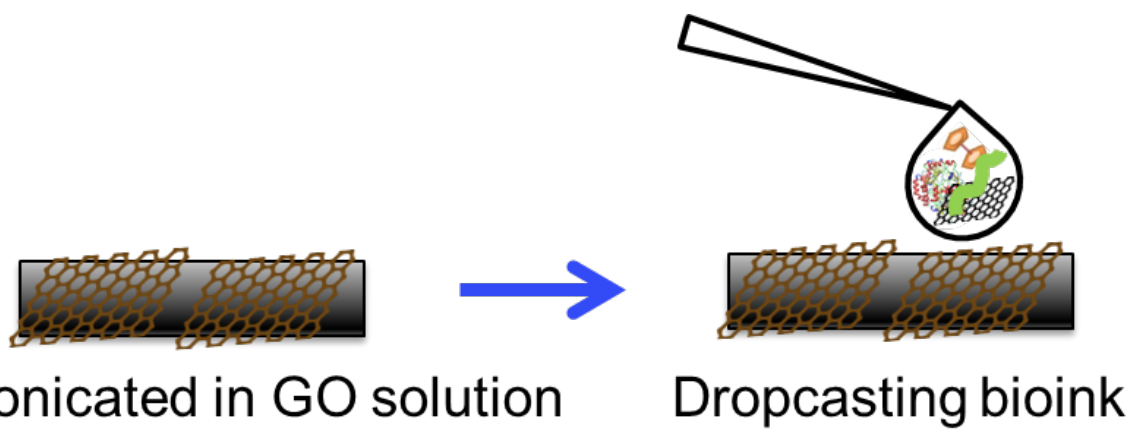

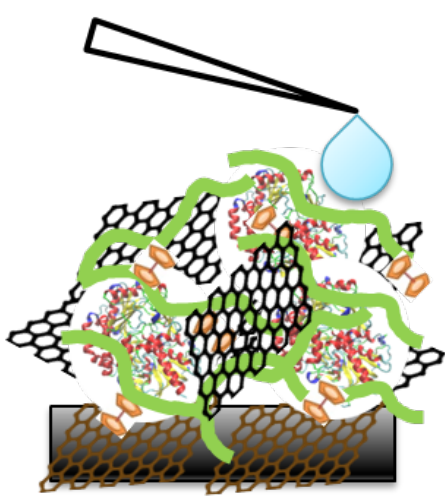

Dropcasting Nafion

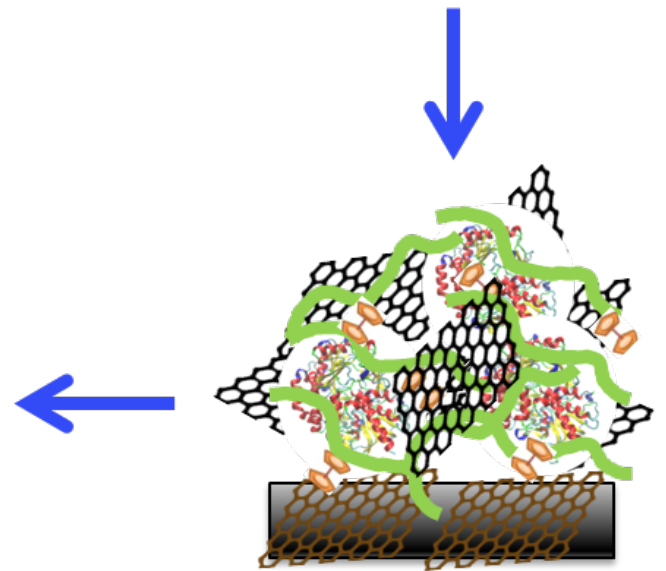

Drying

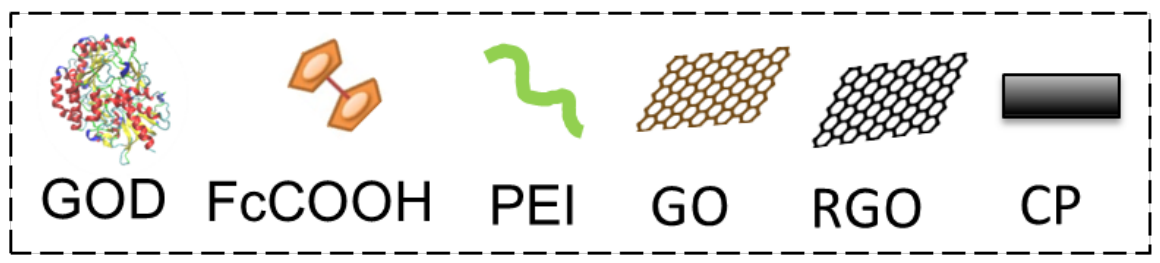

Scheme 1. Schematic illustration of the construction of the GOD-graphene bioelectrode. The bioink consisting of GOD and $\mathrm{FcCOOH}$ in a PEI-graphene matrix is immobilized on CP. A piece of carbon fiber (black) illustrates the interaction of $\mathrm{CP}$ with the ink. The porous $\mathrm{CP}$ structure is not shown.

\section{Experimental}

\subsection{Chemicals and materials}

Potassium permanganate $\left(\mathrm{KMnO}_{4}, \geq 99.9 \%\right)$ was from Merck, and PEI solution $\left(50 \%(\mathrm{w} / \mathrm{v})\right.$ in $\mathrm{H}_{2} \mathrm{O}$, molecular weight $\left.(\mathrm{MW})=750,000 \mathrm{~g} \mathrm{~mol}^{-1}\right)$, potassium dihydrogen phosphate $\left(\right.$ monobasic, $\mathrm{KH}_{2} \mathrm{PO}_{4}$, $\geq 99.995$ ) and potassium monophosphate (dibasic, $\mathrm{K}_{2} \mathrm{HPO}_{4}, \geq 99.999$ ) were from Fluka Analytical. D-(+)-glucose $(\geq 99 \%)$, hydrogen peroxide $\left(\mathrm{H}_{2} \mathrm{O}_{2}, 34.5-36.5 \%\right)$, sulfuric acid $\left(\mathrm{H}_{2} \mathrm{SO}_{4}, 95-97 \%\right)$, graphite powders $(<20 \mu \mathrm{m})$, hydrochloric acid $(\mathrm{HCl}, 37 \%)$, potassium persulfate $\left(\mathrm{K}_{2} \mathrm{~S}_{2} \mathrm{O}_{8}, \geq 99 \%\right)$, 
phosphorous pentoxide $\left(\mathrm{P}_{2} \mathrm{O}_{5}, \geq 98 \%\right.$ ), PEI solution (branched, 50\% wt.\% in $\mathrm{H}_{2} \mathrm{O}, \mathrm{MW}=800$ or $\left.1,300 \mathrm{~g} \mathrm{~mol}^{-1}\right)$, Nafion ${ }^{\circledR}\left(10\right.$ wt. \% dispersion in $\left.\mathrm{H}_{2} \mathrm{O}\right)$ and $\mathrm{FcCOOH}(\geq 97 \%)$ were from Sigma Aldrich. GOD from Aspergillus niger (Type X+S. lyophilized powder, 100,000-250,000 units g ${ }^{-1}$ solid) from Sigma was used without further purification. Absolute ethanol (99.97\%) was from VWR Chemicals.

CP, Nafion 115 exchange membrane and commercial platinum $(\mathrm{Pt})$ cathodes were purchased from Quintech (Germany). The CP, composed of ø 6-8 $\mu \mathrm{m}$ carbon fibers, is untreated Toray carbon paper type EC-TP1-060 with a thickness of $190 \mu \mathrm{m}$. The commercial Pt cathodes (BC-H225-10F) have approximately $1.0 \mathrm{mg}$ Pt nanoparticles $(5 \mathrm{~nm}) \mathrm{cm}^{-2}$ loaded onto carbon fiber of high surface area. ${ }^{44}$

\subsection{GO preparation}

GO was synthesized by the modified Hummer's method. ${ }^{44} 5.0$ g graphite powder was first preoxidized by heating in a solution of $20.0 \mathrm{~mL}$ concentrated sulfuric acid, $2.5 \mathrm{~g}$ phosphorous pentoxide and $2.5 \mathrm{~g}$ potassium persulfate at $80^{\circ} \mathrm{C}$ under stirring for three hours. $120 \mathrm{~mL}$ Millipore water was then slowly added into the hot solution along the flask wall to dilute and cool the solution. The cooled solution was filtered, washed by Millipore water until neutral, and the product, pre-oxidized graphite, then dried at $50{ }^{\circ} \mathrm{C}$ overnight. $1.0 \mathrm{~g}$ of the resulting pre-oxidized graphite powder was mixed with $23.0 \mathrm{~mL}$ concentrated sulfuric acid and $3.0 \mathrm{~g}$ potassium permanganate reacting under magnetic stirring at $35{ }^{\circ} \mathrm{C}$ for $2 \mathrm{~h} .200 \mathrm{~mL}$ of Millipore water was added slowly followed by $2 \mathrm{~mL} \mathrm{H}_{2} \mathrm{O}_{2}$ until no further reaction with bubble formation. The raw GO was filtrated and washed with $250 \mathrm{~mL} 1.0 \mathrm{M}$ hydrochloric acid. The GO solution was finally washed with Millipore water and concentrated by centrifugation followed by dialysis in Millipore water for one week.

\subsection{Bioink and GOD bioelectrode preparation}

Preparation of the bioink and bioelectrode is shown in Scheme 2. A mixture of $17.0 \mathrm{~mL}$ Millipore water and $5.0 \mathrm{mg} \mathrm{FcCOOH}$ was first pre-heated in an oil bath at $95{ }^{\circ} \mathrm{C}$ together with $2.0 \mathrm{~mL} 1.0 \mathrm{mg}$ $\mathrm{mL}^{-1} \mathrm{GO}$ solution under magnetic stirring. $1.0 \mathrm{~mL}$ of $40 \mathrm{mg} \mathrm{mL}^{-1} \mathrm{PEI}\left(\mathrm{MW}=1,300 \mathrm{~g} \mathrm{~mol}^{-1}\right)$ was added and the solution heated for $1 \mathrm{~h}$ at $95{ }^{\circ} \mathrm{C}$. This recipe was used throughout unless otherwise stated. FcCOOH was selected as a mediator, first due to its favorable solubility in aqueous solution in contrast to ferrocene and secondly, as among ferrocene derivatives $\mathrm{FcCOOH}$ is an efficient electron acceptor of GOD. ${ }^{37}$ The resulting RGO-PEI-FcCOOH mixture was concentrated five times to $4 \mathrm{~mL}$ by centrifugation for 20 minutes at 12,000 rpm. Bioink was prepared by mixing $4.0 \mathrm{mg}$ GOD dissolved in $200 \mu \mathrm{L}$ Millipore water and $800 \mu \mathrm{L}$ concentrated RGO-PEI-FcCOOH mixture. To ensure 
efficient electrostatic coupling between the negatively charged GOD and the positively charged PEI, the bioink was subjected to magnetic stirring for 20 hours at $4{ }^{\circ} \mathrm{C}$. To improve the wettability of CP, a $1.0 \times 5.0 \mathrm{~cm}^{2}$ piece of $\mathrm{CP}$ was sonicated in $15 \mathrm{~mL} 1.0 \mathrm{mg} \mathrm{mL}^{-1} \mathrm{GO}$ solution for two hours. This step provides the originally hydrophobic $\mathrm{CP}$ with strongly enough hydrophilicity for use. A $0.5 \times 1.0$ $\mathrm{cm}^{2}$ T-shaped piece (electrode area: $0.5 \times 0.4 \mathrm{~cm}^{2}$ ) was then cut from the CP. $20.0 \mu \mathrm{L}$ of the prepared bioink was dropcasted onto the CP (size: $0.20 \mathrm{~cm}^{2}$ ) and left to dry for $20 \mathrm{~h}$ at $4{ }^{\circ} \mathrm{C}$. Finally, $10.0 \mu \mathrm{L}$ of $1.0 \mathrm{wt} \%$ aqueous Nafion solution was drop-casted onto the GOD bioelectrode before the electrochemical measurements.

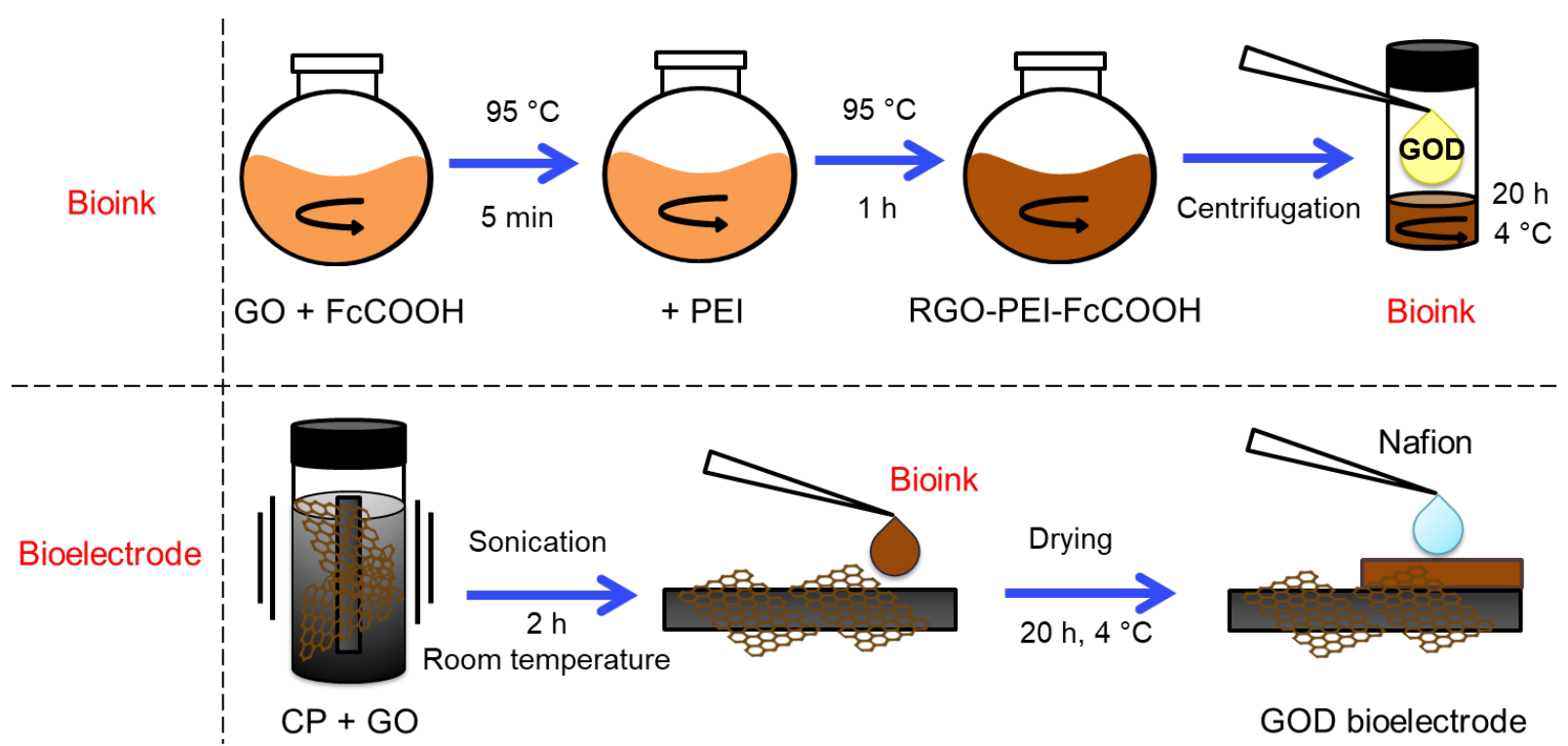

Scheme 2. Schematic illustration of procedure for the bioink and bioelectrode preparations.

\subsection{Electrochemistry}

The electrochemical data were recorded using an Autolab PGSTAT12 (Eco Chemie, Netherlands) with the NOVA 2.1 software. An in-house built reversible hydrogen electrode (RHE) was used as reference electrode and a platinum electrode as counter electrode. The electrolyte was $10.0 \mathrm{~mL}$ of 20 $\mathrm{mM}$ phosphate buffer solution (PBS, $\mathrm{pH}$ 7.0). Before each experiment, the electrolyte was degassed for at least 30 minutes by Ar and an Ar atmosphere above the electrolyte maintained during all electrochemical experiments. A calculated volume of $0.30 \mathrm{M}$ glucose in $20 \mathrm{mM}$ PBS was added into the electrolyte cell to reach the targeted glucose concentration during the experiments. The RHE potential was calibrated vs. a saturated calomel electrode (SCE) after each experiment. All potentials are reported vs. SCE. 


\subsection{Test in biofuel cells}

A biofuel cell station, developed previously in the group, ${ }^{44}$ was constructed and equipped with the optimized bioelectrode as the bioanode, a platinum cathode and a separating membrane between the electrodes. To focus on the development of the GOD-graphene bioanode, a commercial Pt cathode and Nafion perfluorinated ion-exchange membrane were used and assembled under hot-pressing at $135.0{ }^{\circ} \mathrm{C}$ and $120 \mathrm{~kg} \mathrm{~cm}^{-2}$ pressure for 180 seconds. The bioanode was prepared separately (described in Supporting Information) and assembled together with the cathode and Nafion membrane by mechanical forces in the biofuel cell at room temperature, Figure $\mathrm{S} 1$. The EBFC fed with $\mathrm{O}_{2}$ and fuel solution was connected with an Autolab potentiostat under temperature control, Figure S2. The EBFC was assembled with a Teflon window as mechanical protection, graphite blocks as fuel or oxygen suppliers, gold coated plates as current collectors, Teflon sheets as current-leaking protectors, and aluminum blocks as outer protectors, Figure S3 and S4. Before FC testing, the membrane within the EBFC was humidified with water for three to four hours and then by fuel solution ( $50 \mathrm{mM}$ glucose in $20 \mathrm{mM}$ PBS, pH 7.0) for about 30 min using a pump, since the Nafion membrane must be completely wetted in order to conduct protons. The EBFC was heated to $15,25,35$, or $45{ }^{\circ} \mathrm{C}$, and tests with fuel solution supplied at $2.0 \mathrm{~mL} \mathrm{~min}^{-1}$ and dioxygen flow at $100 \mathrm{~mL} \mathrm{~min}^{-1}$ then started.

\subsection{Microscopic characterization}

Atomic force microscopy (AFM) (a 5500 SPM system, Keysight Technologies, Santa Rosa CA, USA) controlled by PicoView combined with a non-conductive silicon nitride tip was used in tapping mode. AFM samples were prepared by dropcasting $10 \mu \mathrm{L} \mathrm{GO}$ solution on a piece of freshly cleaved mica sheets $\left(20 \times 20 \mathrm{~mm}^{2}\right)$ followed by drying at room temperature. Scanning electron microscopy (SEM, FEI Quanta FEG 200 ESEM with an ETD detector, USA) was used for mapping of modified CPelectrodes. X-ray photoelectron (XPS) spectroscopic measurements were carried out using an ESCALABMKII X-ray photoelectron spectrometer (Thermo Scientific).

\section{Results and Discussion}

\subsection{SEM characterization of modified electrodes}

Three dimensional CP consisting of thin interwoven carbon fibers (6-8 $\mu \mathrm{m}$ in diameter, Figure 1a) was chosen as the electrode supporting material, due to its large surface areas, mechanical strength and high conductivity. The macropores allow both the bioink and fuel molecules to diffuse freely into the structure. The mechanical strength and electronic conductivity are robust to the surface modifications. On the other hand, the hydrophobic surface of CP is poorly compatible with the bioink. 
This could be improved by coating with GO (Scheme 1), i.e. sonicating the $\mathrm{CP}$ in an aqueous solution of GO. $\pi-\pi$ packing here plays a role in the surface modification. A similar phenomenon was reported for modification of carbon nanotubes (CNTs) with graphene platelets. ${ }^{45}$ Figure $1 \mathrm{~b}$ and $1 \mathrm{c}$ show small flakes of carbon material on the surface of the $\mathrm{CP}$ after sonication in GO solution, consistent with the GO size $(2-3 \mu \mathrm{m})$ found by AFM (Figure S5a and b). After CP coverage by small hydrophilic GO flakes, the aqueous bioink can spread uniformly over the CP surface, Figure 1d.
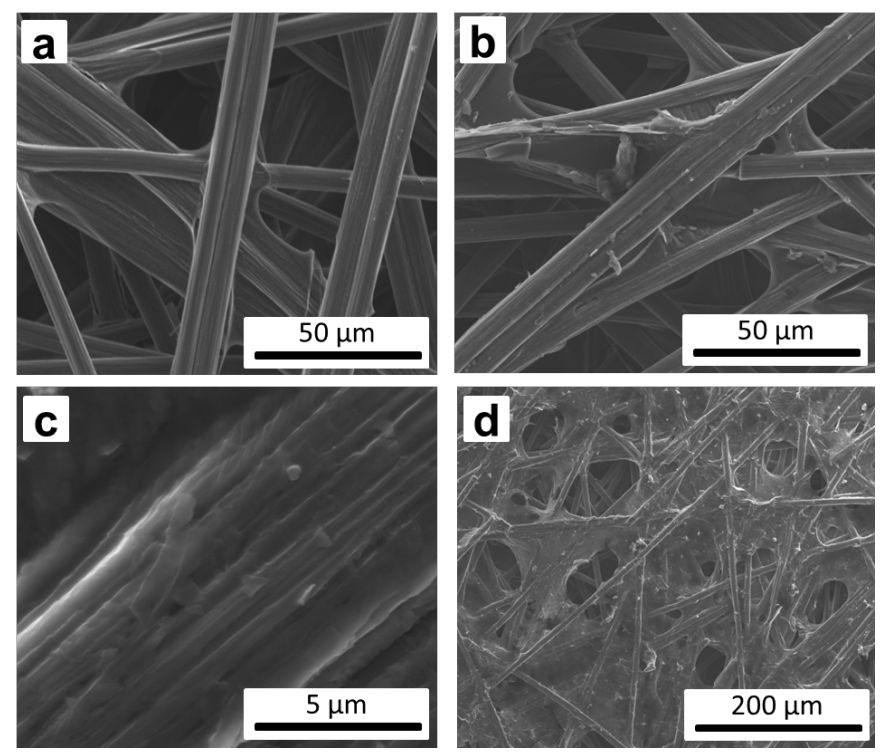

Figure 1. Scanning electron microscopy (SEM) images of (a) bare CP, (b, c) CP with GO (CPG) and (d) the CPG electrode modified with the RGO-PEI-FcCOOH-GOD ink.

XPS characterization of CP, CPG and RGO-PEI-FcCOOH on CPG (CPG_RGO-PEI-FcCOOH) electrodes were carried out to examine the surface properties of the modified electrodes. Figure S6a presents the survey spectra of the modified electrodes, all showing the presence of the elements $\mathrm{O}$ and $\mathrm{C}$. In comparison to the spectrum of $\mathrm{CP}, \mathrm{CPG}$ exhibited a ten-fold $\mathrm{O} 1 \mathrm{~s} / \mathrm{C} 1 \mathrm{~s}$ ratio increase (from 0.026 to 0.270 ), indicative of a large amount of oxygenated species from GO. This demonstrates that GO has indeed been successfully coated onto the carbon fibers, consistent with the SEM observations (Figure 1). The spectrum of CPG_RGO-PEI-FcCOOH electrode showed a clear N 1s peak due to the presence of $\mathrm{PEI}$, and a minor peak assigned to $\mathrm{FcCOOH}$.

Detailed C 1s spectra can be fitted well by several carbon-based peaks, including C-sp ${ }^{2}, \mathrm{C}-\mathrm{sp}^{3}, \mathrm{C}-\mathrm{N}$, $\mathrm{C}-\mathrm{O}, \mathrm{C}=\mathrm{O}$ and $\mathrm{COOH}$, Figure S6b-d. Their peak area ratios relative to the total carbon species are summarized in Table S1. The main carbon component for bare CP was C-sp ${ }^{2}$ (70.9\%), while the total oxygenated carbon species, i.e., $\mathrm{C}-\mathrm{O}, \mathrm{C}=\mathrm{O}$, and $\mathrm{COOH}$, only take up $11.3 \%$. After coating of the $\mathrm{CP}$ 
with GO, the relative amount of oxygenated carbon species drastically increased from $7.1 \%, 1.4 \%$, and $2.8 \%$ for CP to $29.6 \%, 3.0 \%$, and $4.0 \%$ for CPG, respectively (Table S1). The presence of PEI on the CPG_RGO-PEI-FcCOOH electrode resulted in the appearance of C-N on the modified electrode (23.2\%). All these observations demonstrated the successful functionalization of RGO-PEI$\mathrm{FcCOOH}$ on the CPG electrode.

\subsection{Voltammetry of the GOD bioelectrode}

The voltammetry of the GOD bioelectrodes in the absence of glucose was first evaluated. A pair of well-defined and quasi-reversible redox peaks with an apparent formal potential of $0.285 \mathrm{~V}$ vs. SCE is observed only for RGO-PEI-FcCOOH-GOD ink (CPG+GOD ink) (red curve, Figure 2a), corresponding to the redox process of $\mathrm{FcCOOH}$, Eq. 1. ${ }^{37,46}$ Both cathodic and anodic currents increase linearly with scan rate in a range 10 to $100 \mathrm{mV} \mathrm{s}^{-1}$, Figure $2 \mathrm{~b}$. This suggests that the immobilized redox species exhibits surface-controlled electrochemical behavior. The surface coverage $(\Gamma)$ of $\mathrm{FcCOOH}$ was calculated from the linear fitting of the peak current density $\left(\mathrm{I}_{\mathrm{p}} / \mathrm{A}_{\mathrm{G}}\right)$ vs. scan rate (Figure 2c) according to Eq. S3, S4 and S5. ${ }^{47-48}$ The estimated $\Gamma$ of $\mathrm{FcCOOH}$ is $1.12 \pm 0.06 \times 10^{-10}$ $\mathrm{mol} \mathrm{cm}{ }^{-2}$. As control experiments, bare CP (black curve) and CP coated with GO (CPG) (green curve) give peak-less voltammetry in the same potential region, Figure $2 \mathrm{a}$. In addition, the estimated apparent rate constant of $\mathrm{FcCOOH}$ on the bioelectrodes is $0.71 \mathrm{~s}^{-1}$ based on the Laviron equation (Figure S7). ${ }^{49}$ Overall, these data show that the negatively charged $\mathrm{FcCOOH}$ is preserved in the positively charged PEI matrix through electrostatic interaction and electrons can communicate rapidly with the bioelectrode.

$$
\mathrm{FcCOOH}\left(\mathrm{Fe}^{\mathrm{II}}\right) \Leftrightarrow \mathrm{Fc}^{+} \mathrm{COOH}\left(\mathrm{Fe}^{\mathrm{III}}\right)+\mathrm{e}^{-}
$$
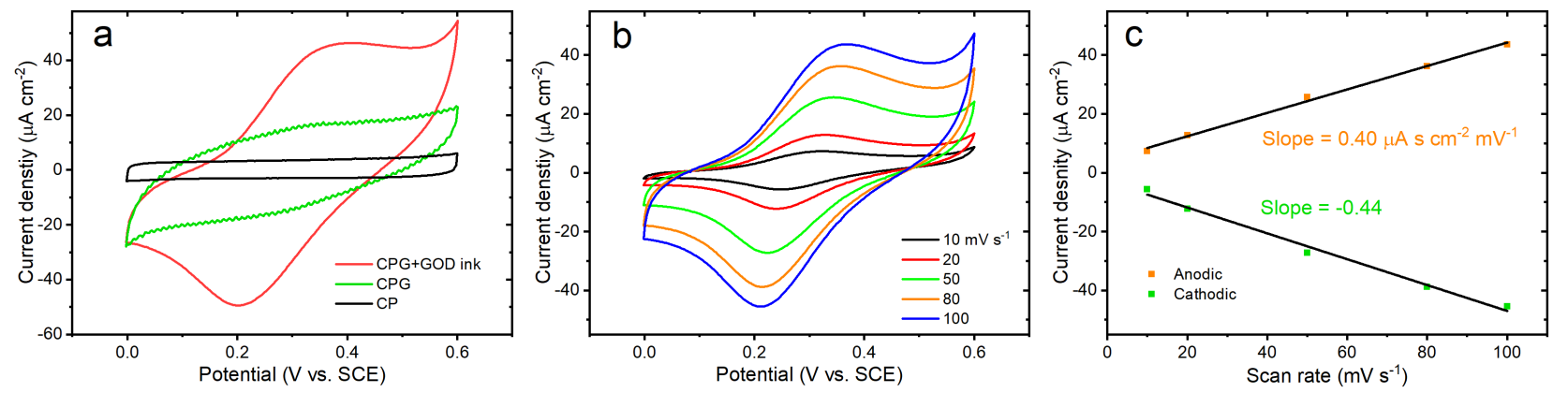

Figure 2. (a) Cyclic voltammograms (CVs) of bare CP (black), CP sonicated with GO (GPG) (green), and the bioelectrode, i.e., CPG electrode with RGO-PEI-FcCOOH-GOD ink (CPG+GOD ink) (red) in $20 \mathrm{mM}$ PBS (pH 7.0). Scan rate: $100 \mathrm{mV} \mathrm{s}^{-1}$. (b) CVs of the bioelectrode (RGO-PEI-FcCOOH-GOD) scanned at 10, 20, $50,80,100 \mathrm{mV} \mathrm{s}^{-1}$ in $20 \mathrm{mM}$ PBS (pH 7.0) and (c) the corresponding linear fitting of the peak current density vs. scan rate. 


\subsection{Electrocatalytic voltammetry of the GOD bioelectrode}

The bioelectrocatalytic oxidation of glucose at the bioelectrode (CPG+GOD ink) is well illustrated by $\mathrm{CV}$, Figure 3a. The anodic current increases, along with reduction of the cathodic peak with increasing glucose concentration. The onset potential for glucose oxidation is $\sim 0.13 \mathrm{~V}$ vs. SCE and the background-corrected catalytic current density $9.7 \mu \mathrm{A} \mathrm{cm}^{-2}$ in the presence of $48 \mathrm{mM}$ glucose. These are typical characteristics of ferrocene-mediated electrocatalytic oxidation of glucose catalyzed by GOD, which can be described as: ${ }^{37,50-52}$

$$
\begin{gathered}
\mathrm{GOD}(\mathrm{FAD})+\text { glucose }\left(\mathrm{C}_{6} \mathrm{H}_{12} \mathrm{O}_{6}\right) \rightarrow \mathrm{GOD}\left(\mathrm{FADH}_{2}\right)+\text { gluconolactone }\left(\mathrm{C}_{6} \mathrm{H}_{10} \mathrm{O}_{6}\right) \\
\mathrm{GOD}\left(\mathrm{FADH}_{2}\right)+2 \mathrm{Fc}^{+} \mathrm{COOH}\left(\mathrm{Fe}^{\mathrm{III}}\right) \rightarrow \mathrm{GOD}(\mathrm{FAD})+2 \mathrm{FcCOOH}\left(\mathrm{Fe}^{\mathrm{II}}\right)+2 \mathrm{H}^{+}
\end{gathered}
$$

where $\mathrm{GOD}(\mathrm{FAD})$ and $\mathrm{GOD}\left(\mathrm{FADH}_{2}\right)$ represent the oxidized and reduced form of GOD, respectively. The anodic catalytic current vs. glucose concentration (calibration curve for a glucose biosensor) shows a linear relationship up to $48 \mathrm{mM}$, Figure $3 \mathrm{~b}$. Such a wide linear range, benefiting from the bilayer polymer coating on the bioelectrode that buffers enzyme substrate diffusion to the enzyme, ${ }^{53}$ covers the normal blood glucose concentration (typically $2-10 \mathrm{mM}$ ), ${ }^{54}$ and shows the potential of the new bioink material in a glucose biosensor. Furthermore and notably, the GOD bioelectrode shows a very wide linear range among recently reported glucose GOD biosensor, Table $\mathrm{S} 2$. The relatively low sensitivity $\left(0.20 \mu \mathrm{A} \mathrm{mM}-1 \mathrm{~cm}^{-2}\right)$ is mainly caused by the diffusion effect. The biocatalytic current variation with increasing substrate concentrations formally follows Michaelis-Menten enzyme kinetics, illustrated in the Lineweaver-Burk format, Figure S8, Eq. S6, S7 and S8. The apparent Michaelis constant, $K_{M}^{a p p}$, of the bioelectrode was $19 \pm 2 \mathrm{mM}$, which is, however, higher than the value of $0.60 \mathrm{mM}$ obtained from the GOD graphene-based glassy carbon electrode. ${ }^{55}$
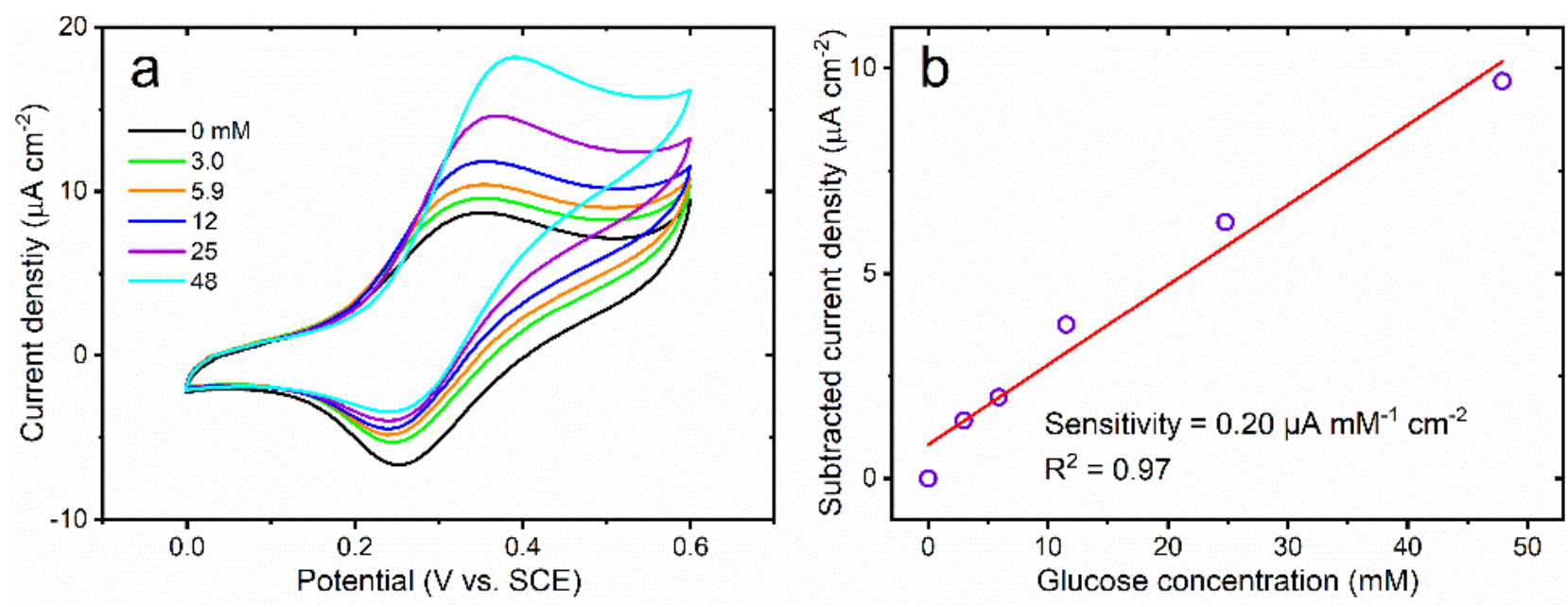
Figure 3. (a) CVs of the bioelectrode (RGO-PEI-FcCOOH-GOD) towards different glucose concentrations in $20 \mathrm{mM}$ PBS (pH 7.0) at $10 \mathrm{mV} \mathrm{s}^{-1}$ and (b) the corresponding background-subtracted current density of anodic peak vs. glucose concentration.

\subsection{Optimization of ink composition for the GOD bioelectrode}

The GOD-bioanode performance depends significantly on the bioanode composition, particularly the bioink properties, the optimization of which was studied further.

Graphene is crucial in the GOD bioelectrode, serving as the conductive linker between ink components and the electrode surface. Graphene was obtained by reducing GO, i.e. heating GO together with PEI during the synthesis of the ink. The bioelectrodes prepared with various amounts of $\mathrm{GO}(0,1,2$ and $4 \mathrm{mg})$ during the bioink synthesis were fabricated with their electrocatalytic response recorded. The bioelectrode without GO showed the lowest electrocatalytic current toward glucose oxidation (black curve in Figure $4 \mathrm{a}$ ). The peak-peak separation, $\Delta \mathrm{E}_{\mathrm{p}}$ decreased from 104 to $82 \mathrm{mV}$ in the presence of $2 \mathrm{mg} \mathrm{GO}$, implying faster electron transfer of the redox process $\mathrm{FcCOOH}$ on the electrode surface. The noncatalytic response of the bioelectrode furthermore doubled and the catalytic response tripled, Figure 4b. Even small amounts of graphene (i.e. $1.0 \mathrm{mg}$ GO) drastically increases the initial activity, but the stability is poor, probably due to the unstable conductive relays (green in Figure 4a). Increasing the concentration of graphene to $4 \mathrm{mg}$ in the ink, the electrocatalytic activity decreased, but better stability was achieved. $2.0 \mathrm{mg}$ GO was therefore chosen for further study.

PEI plays key roles both as the reducing agent of GO and as a matrix for enzyme immobilization. PEI can also contribute to reduce GO. ${ }^{46}$ It was observed that the mixed solution of GO, PEI and FcCOOH changes color from brown (GO) to black (RGO) during the synthesis, Figure S5c. PEI is protonated and positively charged, whereas GOD is negatively charged at neutral $\mathrm{pH}$, as the isoelectric points of $\mathrm{PEI}^{43}$ and $\mathrm{GOD}^{56}$ are ca. 10 and 4.2, respectively. Electrostatic interaction is therefore important in holding PEI and GOD firmly together in the ink. In this work we used inks containing PEI with MW of $800,1,300$ and $750,000 \mathrm{~g} \mathrm{~mol}^{-1}$, respectively. The highest activity was from the electrodes with PEI (MW 1,300 $\mathrm{g} \mathrm{mol}^{-1}$ ) (red in Figure 4c). The bioelectrodes with PEI (MW $800 \mathrm{~g} \mathrm{~mol}^{-1}$ ) (black in Figure 4c) do not show any catalytic response, probably because the polymer with shorter chains exhibits weaker dispersion ability and results in more aggregation of components in the GOD ink. PEI with a large MW (750,000 $\left.\mathrm{g} \mathrm{mol}^{-1}\right)$ generates low catalytic currents (green in Figure 4c) in comparison to that with a moderate $\mathrm{MW}\left(1,300 \mathrm{~g} \mathrm{~mol}^{-1}\right)$, Figure $4 \mathrm{~d}$. 

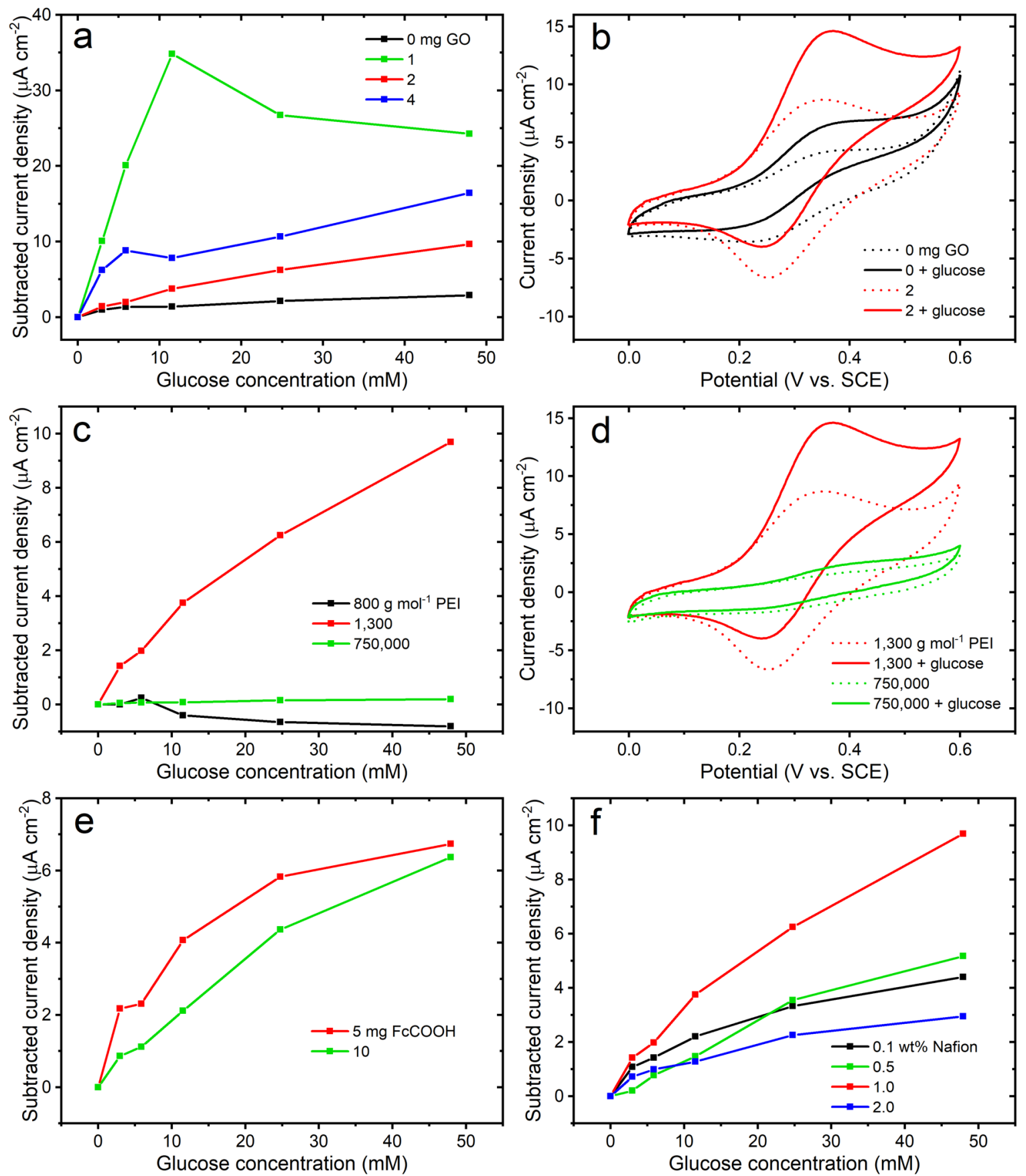

Figure 4. Background-subtracted current density as a function of glucose concentration for the bioelectrode with GOD inks synthesized (a) with various GO concentrations (0, 1, 2, $4 \mathrm{mg}$ ); (c) various MWs of PEI, (800, 1300, $750000 \mathrm{~g} \mathrm{~mol}^{-1}$ ); (e) 5 or $10 \mathrm{mg} \mathrm{FcCOOH}$; (f) Nafion with different concentrations (0.1, 0.5, 1.0, 2.0 wt\%). CVs of the bioelectrode with GOD ink synthesized (b) with or without $2 \mathrm{mg} \mathrm{GO}$, and (d) with PEI MWs of 1300 or $750000 \mathrm{~g} \mathrm{~mol}^{-1}$ in the absence (dashed line) and presence of $25 \mathrm{mM}$ glucose (solid line), respectively. The effect of the amount of $\mathrm{FcCOOH}(5$ and $10 \mathrm{mg})$ in the synthesis of $4 \mathrm{~mL}$ ink with $0.5 \mathrm{mg} \mathrm{mL}^{-1}$ RGO and $10 \mathrm{mg} \mathrm{mL}^{-1}$ PEI on the performance of the bioelectrode was further evaluated. $5 \mathrm{mg}$ $\mathrm{FcCOOH}$ added to the ink is already at the saturation level, reflected by a comparable catalytic current 
density observed on the electrode with $10 \mathrm{mg} \mathrm{FcCOOH}$ in the ink, Figure 4e. The amount of FcCOOH bound in the PEI-matrix is believed to be saturated and the extra mediator is thus left in the supernatant, confirmed by the observation of an intense yellow color due to the presence of $\mathrm{FcCOOH}$ when the ink is concentrated by centrifugation.

Nafion is a polymer composed of sulfonated tetrafluoropolyethylene, through which small molecules or ions such as protons can diffuse and migrate freely. However, Nafion can denature enzymes by creating an acidic environment. ${ }^{57-58}$ Previous work has shown that the acidic poly(acrylic acid) polymer denatures lactate oxidase (LOD), while enhancing the response of the acidic polymer coating in the Os-complex modified redox polymer/LOD bioelectrode. ${ }^{53}$ Nafion was therefore only used as the second coating layer without direct contact with enzyme and is applied onto the bioelectrode only after the GOD ink has dried on the CPG electrode. The presence of a Nafion layer prevents leakage of the non-covalently bound $\mathrm{FcCOOH}$ and thus enhances the stability of the GOD bioelectrode. With a $\mathrm{pK}_{\mathrm{a}}$ value of $7.2,{ }^{59} \mathrm{FcCOOH}$ binds electrostatically in the $\mathrm{Fc}^{+} \mathrm{COO}^{-}$form to the protonated amines of PEI, but leakage of FcCOOH from the electrode can reduce the catalytic activity. Figure $4 \mathrm{f}$ shows the electrocatalytic current of the GOD bioanode as a function of glucose and Nafion concentrations. A thin layer of Nafion (made from 0.1 and $0.5 \mathrm{wt} \%$ ) cannot efficiently prevent the leakage and thus results in low activity, but a thick layer with a high concentration of Nafion (e.g. $2.0 \mathrm{wt} \%$ ) increases the resistance for mass transport of glucose and gives a poor catalytic response. The optimal Nafion concentration was found to be $1.0 \mathrm{wt} \%$. Based on these control experiments, the bioelectrodes were

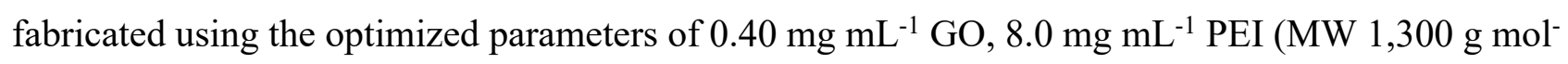
${ }^{1}$ ), $1.0 \mathrm{mg} \mathrm{mL}^{-1} \mathrm{FcCOOH}$, and $0.40 \mathrm{mg} \mathrm{mL}^{-1} \mathrm{GOD}$ for the synthesis of GOD ink, with $10 \mu \mathrm{L} 1.0 \mathrm{wt} \%$ Nafion solution dropcasted on top of the bioelectrodes (geometric area: $0.20 \mathrm{~cm}^{2}$ ).

\subsection{Evaluation of the optimized bioelectrode}

We investigated further the storage stability and $\mathrm{pH}$-dependent performance of the optimized GODgraphene bioelectrode. A series of GOD bioelectrodes were prepared and stored at $4{ }^{\circ} \mathrm{C}$ in the dried state, and the electrochemical performance in the absence (noncatalytic activity) or presence (catalytic activity) of glucose tested after storage up to 7 days. The bioelectrodes maintain comparable activity with the freshly prepared electrode after two days' storage, Figure 5a. However, the activity decreases by $28 \%$, while the noncatalytic current density drops slightly after one-week's storage, Figure $5 \mathrm{a}$. This strongly suggests that the enzymes denature during storage in the dried state due to loss of moisture in the electrode. 
Solution $\mathrm{pH}$ affects the activity of the GOD bioelectrodes, because the key components of the ink, i.e. enzyme, mediator and PEI are all $\mathrm{pH}$-sensitive. The activity of the GOD-graphene electrode in 20 $\mathrm{mM}$ PBS with $\mathrm{pH}$ ranging from 5.3 to 8.1 was systematically tested. The corresponding electrocatalytic activity as a function of $\mathrm{pH}$ is shown in Figure $5 \mathrm{~b}$. The maximum catalytic current is at $\mathrm{pH} 7.0$, consistent with reports on the optimized $\mathrm{pH}$ for immobilized GOD activity. ${ }^{60} \mathrm{This} \mathrm{pH}$ is very suitable for the mediator attached to PEI and the electrostatic interaction between PEI and GOD. Since the isoelectric point of PEI is above 10, the polymer is positively charged in the $\mathrm{pH}$-range tested. The negative charge of GOD is moderately high at $\mathrm{pH}$ 7.0, together with GOD activity maintained. GOD starts to denature and loses activity at $\mathrm{pH}>8$, resulting in reduced catalytic activity of the bioelectrodes. ${ }^{61}$
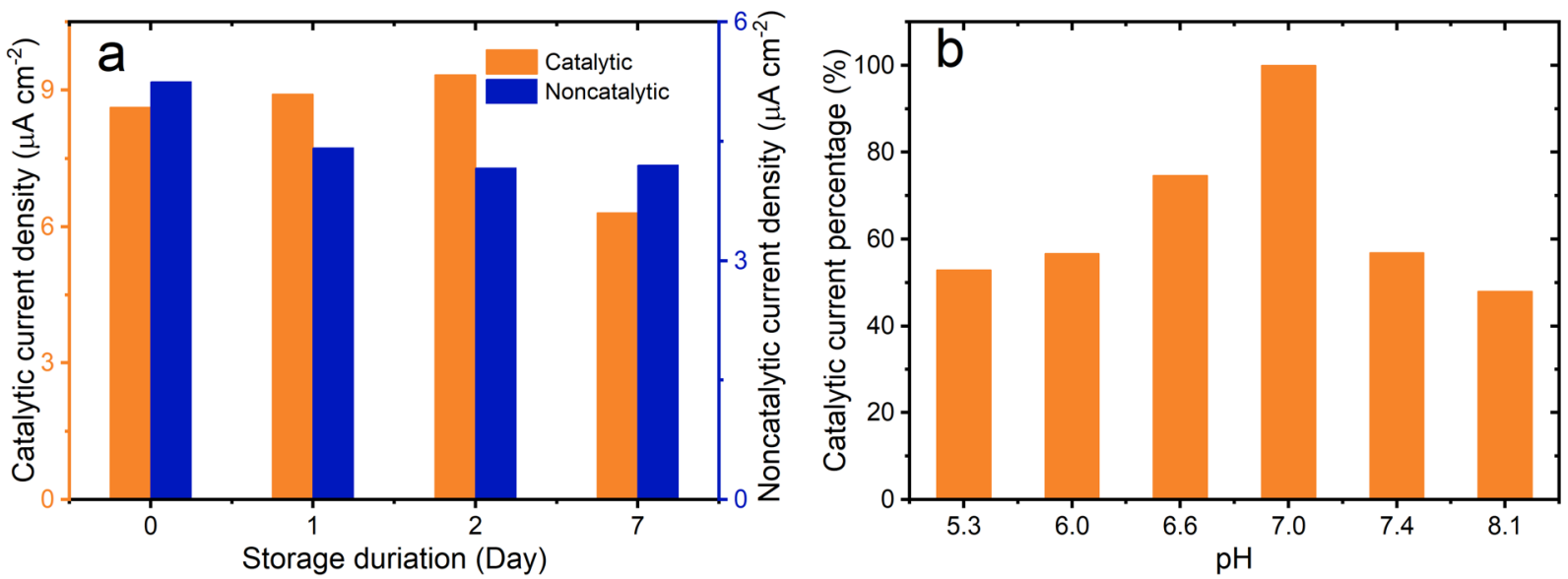

Figure 5. (a) Catalytic and noncatalytic activity of the GOD bioelectrode with different storage durations in the presence and absence of $25 \mathrm{mM}$ glucose in $20 \mathrm{mM} \mathrm{pH} 7.0$ PBS. (b) The effect of $\mathrm{pH}$ in the range 5.3 to 8.1 on the bioelectrode catalytic performance towards $25 \mathrm{mM}$ glucose.

\subsection{GOD bioelectrodes as bioanodes in EBFCs}

We also investigated the GOD bioelectrode as a bioanode in an EBFC, combined with a cathode with commercial Pt catalysts, Figure 6a. This EBFC represents an environmentally friendly approach to convert chemical energy stored in fuel molecules to electricity. The cheap and robust GOD is a suitable biocatalyst for the bioanode and can catalyze the oxidation of glucose. The polarization and power density curves of the EBFC were recorded, Figure 6b. As a control, a cell using CPG electrode without GOD was also studied. The EBFC shows a maximum power density $\left(\mathrm{P}_{\max }\right)$ of $5.12 \mu \mathrm{W} \mathrm{cm}{ }^{-2}$ with an open circuit voltage $(\mathrm{OCV})$ of $0.40 \mathrm{~V}$, notably outperforming the control FCs $\left(\mathrm{P}_{\max }=1.18\right.$ $\mu \mathrm{W} \mathrm{cm}{ }^{-2}$; OCV $=0.28 \mathrm{~V}$ ). This means that the GOD bioelectrode works well with high catalytic activity in the EBFC. 
The stability of the EBFC was further investigated. The maximum power density was plotted vs. the number of consecutive measurements, Figure S9a. The maximum power density increased at the early measurement and then almost stabilized after the fourth measurements. Since GOD is regarded as a reasonably stable enzyme under operation, ${ }^{62}$ denaturation of GOD is not mostly likely to be the main reason for the gradually decreasing bioelectrocatalytic activity. The continuous CV of the prepared GOD bioanode, Figure S10, with a steady degradation of the redox peaks assigned to the redox process of $\mathrm{FcCOOH}$, instead implies that the mediator leaks from the modified electrode. It can therefore be concluded that the detachment of $\mathrm{FcCOOH}$ plays the key role in the decreased performance of the bioanode. $\mathrm{P}_{\max }$ for the sixth measurements fluctuated around $2.1 \pm 0.1 \mu \mathrm{W} \mathrm{cm}{ }^{-2}$ (Figure S9a), indicating that the EBFC shows good stability and reproducibility. Power outputs of the EBFC at the sixth measurement were recorded at different temperature, Figure S9b. $\mathrm{P}_{\max }$ of EBFCs increases from 1.5 to $2.5 \mu \mathrm{W} \mathrm{cm}{ }^{-2}$ with operation temperature increasing from 15 to $35{ }^{\circ} \mathrm{C}$ and then drops to $2.4 \mu \mathrm{W} \mathrm{cm}{ }^{-2}$ at $45{ }^{\circ} \mathrm{C}$. The decreased power density of the EBFCs at $45{ }^{\circ} \mathrm{C}$ is due to the instability of the GOD bioanode at such temperature, Figure S9b. Notably, the EBFC power density reaches a maximum at $35^{\circ} \mathrm{C}$, which is the highest activity of the GOD bioelectrode. This is different from conventional fuel cells, which show the maximum power output at $80^{\circ} \mathrm{C} .{ }^{44}$ The main reason for our low optimized temperature is consistent with the stability of the enzyme.
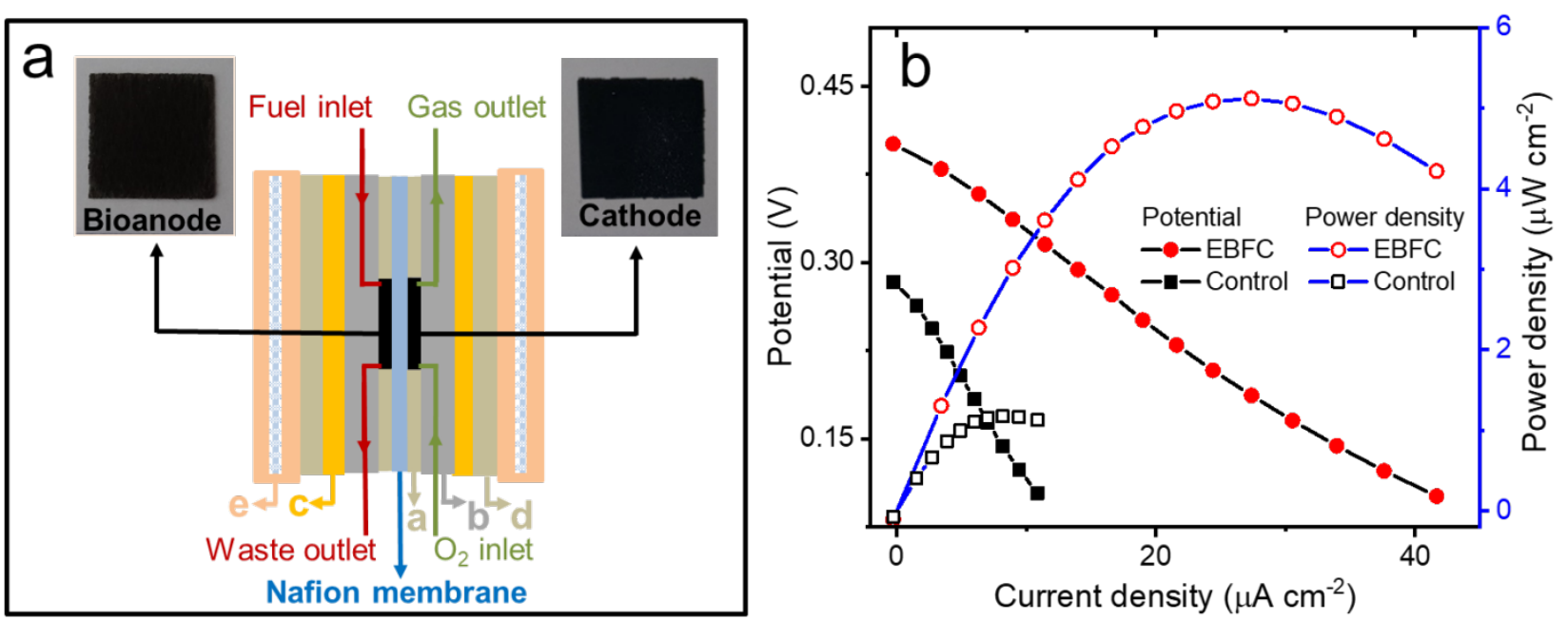

Figure 6. (a) Schematic illustration of an assembled EBFC, a, b, c, d to e: Teflon gaskets, graphite blocks, Auplated current collectors, Teflon sheets, and Aluminum blocks inserted with heaters. (b) Polarization and power density curves of an EBFC and a control FC with CPG electrode as the anode at $25^{\circ} \mathrm{C}$, fed with $20 \mathrm{mM} \mathrm{PBS}$ (pH 7.0) containing $50 \mathrm{mM}$ glucose $\left(2 \mathrm{~mL} \mathrm{~min}^{-1}\right)$ at the anode and dioxygen-saturated PBS $\left(100 \mathrm{~mL} \mathrm{~min}^{-1}\right)$ at the cathode.

\section{Conclusion and perspectives}


A facile method to prepare a new kind of bioelectrode by drop-casting a systematically explored bioink onto a 3D porous CP electrode has been developed. The CP provides a mechanically strong 3D skeleton. The bioink comprises GOD co-immobilized with $\mathrm{FcCOOH}$ mediator in a matrix of polymer PEI and graphene. The ink composition is essential to ensure electronic conductivity, activity, and stability of the bioelectrode. The optimized parameters for synthesis of bioink are $0.40 \mathrm{mg} \mathrm{mL}^{-1}$ GO, $8.0 \mathrm{mg} \mathrm{mL}^{-1}$ PEI (MW 1,300 $\mathrm{g} \mathrm{mol}^{-1}$ ), $1.0 \mathrm{mg} \mathrm{mL}^{-1} \mathrm{FcCOOH}$, and $0.40 \mathrm{mg} \mathrm{mL}^{-1} \mathrm{GOD}$.

The bioelectrode can potentially be used as a glucose biosensor with a wide linear range ( 3 to $48 \mathrm{mM}$ ) toward the substrate, which covers the glucose concentration in blood for both healthy human beings and diabetes patients. The significantly improved linear range is due to the diffusion effect at the 3D structure of CP. The bioelectrodes are broadly stable for up to one week's storage at $4{ }^{\circ} \mathrm{C}$ with only a $20 \%$ decay of the catalytic activity. Additionally, the GOD bioelectrode was successfully inserted as the anode into an EBFC with commercial Pt cathodes, verifying its applications in biofuel cells. The EBFC with satisfactory stability provided a maximum power density of $5.1 \mu \mathrm{W} \mathrm{cm}^{-2}$ with OCV of $0.40 \mathrm{~V}$ at $25^{\circ} \mathrm{C}$. Although the stability and power output of the EBFCs is not fully comparable to reported glucose EBFCs, the response range of the bioelectrode as glucose biosensor is wider than recently reported graphene-based glucose biosensors. In addition, the strategy for bioelectrode fabrication by simply drop-casting a bioink is general and therefore can most likely be applied to other enzymes, mediators and polymers in the ink, or by functionalization of the ink.

\section{Acknowledgements}

Financial support from The Danish Council for Independent Research for the YDUN project (DFF 4093-00297), the Carlsberg foundation (2012_01_0520) and the Russian Science Foundation (project № 17-13-01274) is gratefully acknowledged. This project has also received funding from the European Union's Horizon 2020 research and innovation programme under the Marie SkłodowskaCurie grant agreement No. 713683.

\section{References}

1. Tavahodi, M.; Schulz, C.; Assarsson, A.; Ortiz, R.; Ludwig, R.; Cabaleiro-Lago, C.; Haghighi, B.; Gorton, L., J. Electroanal. Chem., 819, 226-233 (2018).

2. Van Nguyen, K.; Giroud, F.; Minteer, S. D., J. Electrochem. Soc., 161 (14), H930-H933 (2014).

3. Xiao, X.; Xia, H.-q.; Wu, R.; Bai, L.; Yan, L.; Magner, E.; Cosnier, S.; Lojou, E.; Zhu, Z.; Liu, A., Chem. Rev., 119 (16), 9509-9558 (2019). 
4. Rasi, M.; Rajendran, L.; Sangaranarayanan, M. V., J. Electrochem. Soc., 162 (9), H671-H680 (2015).

5. Paul, M. T. Y.; Kinkead, B.; Gates, B. D., J. Electrochem. Soc., 161 (2), B3103-B3106 (2014).

6. Kar, P.; Wen, H.; Li, H.; Minteer, S. D.; Calabrese Barton, S., J. Electrochem. Soc., 158 (5), B580-B586 (2011).

7. Creanga, C.; El Murr, N., J. Electroanal. Chem., 656 (1), 179-184 (2011).

8. Shim, J.; Kim, G.-Y.; Moon, S.-H., J. Electroanal. Chem., 653 (1), 14-20 (2011).

9. Wang, Y.; Zhang, L.; Cui, K.; Ge, S.; Zhao, P.; Yu, J., ACS Appl. Mater. Interfaces, 11 (5), 5114-5122 (2019).

10. Xia, H.-q.; Kitazumi, Y.; Shirai, O.; Kano, K., J. Electroanal. Chem., 763, 104-109 (2016).

11. Hanefeld, U.; Gardossi, L.; Magner, E., Chem. Soc. Rev., 38 (2), 453-468 (2009).

12. Sheldon, R. A.; van Pelt, S., Chem. Soc. Rev., 42 (15), 6223-6235 (2013).

13. Rodrigues, R. C.; Ortiz, C.; Berenguer-Murcia, Á.; Torres, R.; Fernández-Lafuente, R., Chem. Soc. Rev., 42 (15), 6290-6307 (2013).

14. Zhao, C. E.; Gai, P.; Song, R.; Chen, Y.; Zhang, J.; Zhu, J. J., Chem. Soc. Rev., 46 (5), 1545-1564 (2017).

15. Kalathil, S.; Pant, D., RSC Adv., 6 (36), 30582-30597 (2016).

16. Fang, L.; Liu, B.; Liu, L.; Li, Y.; Huang, K.; Zhang, Q., Sensor. Actuat. B-Chem., 222, 1096-1102 (2016).

17. Frasca, S.; Rojas, O.; Salewski, J.; Neumann, B.; Stiba, K.; Weidinger, I. M.; Tiersch, B.; Leimkühler, S.; Koetz, J.; Wollenberger, U., Bioelectrochemistry, 87 (Supplement C), 33-41 (2012).

18. Halder, A.; Zhang, M.; Chi, Q., Biosens. Bioelectron., 87, 764-771 (2017).

19. Kang, Z.; Jiao, K.; Cheng, J.; Peng, R.; Jiao, S.; Hu, Z., Biosens. Bioelectron., 101, 60-65 (2018).

20. Pankratov, D.; Shen, F.; Ortiz, R.; Toscano, M. D.; Thormann, E.; Zhang, J.; Gorton, L.; Chi, Q., Chem. Commun., 54 (83), 11801-11804 (2018).

21. Wang, L.; Zhang, H.; Ching, C.-B.; Chen, Y.; Jiang, R. J. A. M.; Biotechnology, Appl. Microbiol. Biot., 94 (5), 1233-1241 (2012).

22. Wang, L.; Xu, R.; Chen, Y.; Jiang, R., J. Mol. Catal. B-Enzym., 69 (3), 120-126 (2011).

23. Seselj, N.; Engelbrekt, C.; Zhang, J., Sci. Bull., 60 (9), 864-876 (2015).

24. Zhang, Y.; Wu, C.; Zhang, J.; Guo, S., J. Electrochem. Soc., 164 (2), B29-B33 (2017).

25. Song, Y.; Luo, Y.; Zhu, C.; Li, H.; Du, D.; Lin, Y., Biosens. Bioelectron., 76, 195-212 (2016).

26. Dey, R. S.; Hjuler, H. A.; Chi, Q., J. Mater. Chem. A, 3 (12), 6324-6329 (2015). 
27. Xu, Y.; Sheng, K.; Li, C.; Shi, G., ACS Nano, 4 (7), 4324-4330 (2010).

28. Dong, X.; Wang, X.; Wang, L.; Song, H.; Zhang, H.; Huang, W.; Chen, P., ACS Appl. Mater. Interfaces, 4 (6), 3129-3133 (2012).

29. Chen, H.; Müller, M. B.; Gilmore, K. J.; Wallace, G. G.; Li, D., Adv. Mater., 20 (18), 3557-3561 (2008).

30. Shen, F.; Pankratov, D.; Halder, A.; Xiao, X.; Toscano, M. D.; Zhang, J.; Ulstrup, J.; Gorton, L.; Chi, Q., Nanoscale Adv., (2019).

31. Shen, F.; Pankratov, D.; Pankratova, G.; Toscano, M. D.; Zhang, J.; Ulstrup, J.; Chi, Q.; Gorton, L., Bioelectrochemistry, 128, 94-99 (2019).

32. Tang, J.; Werchmeister, R. M. L.; Preda, L.; Huang, W.; Zheng, Z.; Leimkühler, S.; Wollenberger, U.; Xiao, X.; Engelbrekt, C.; Ulstrup, J.; Zhang, J., ACS Catal., 9 (7), 6543-6554 (2019).

33. Kalisz, H. M.; Hendle, J.; Schmid, R. D. J. A. M.; Biotechnology, Appl. Microbiol. Biot., 47 (5), 502-507 (1997).

34. Ivnitski, D.; Branch, B.; Atanassov, P.; Apblett, C., Electrochem. Commun., 8 (8), 1204-1210 (2006).

35. Bartlett, P. N.; Al-Lolage, F. A., J. Electroanal. Chem., 819, 26-37 (2018).

36. Rabti, A.; Raouafi, N.; Merkoçi, A., Carbon, 108, 481-514 (2016).

37. Cass, A. E. G.; Davis, G.; Francis, G. D.; Hill, H. A. O.; Aston, W. J.; Higgins, I. J.; Plotkin, E. V.; Scott,

L. D. L.; Turner, A. P. F., Anal. Chem., 56 (4), 667-671 (1984).

38. Merchant, S. A.; Tran, T. O.; Meredith, M. T.; Cline, T. C.; Glatzhofer, D. T.; Schmidtke, D. W., Langmuir, 25 (13), 7736-7742 (2009).

39. Merchant, S. A.; Meredith, M. T.; Tran, T. O.; Brunski, D. B.; Johnson, M. B.; Glatzhofer, D. T.; Schmidtke, D. W., J. Phys. Chem. C, 114 (26), 11627-11634 (2010).

40. Aquino Neto, S.; Milton, R. D.; Hickey, D. P.; De Andrade, A. R.; Minteer, S. D., J. Power Sources, 324, 208-214 (2016).

41. Escalona-Villalpando, R. A.; Reid, R. C.; Milton, R. D.; Arriaga, L. G.; Minteer, S. D.; Ledesma-García, J., J. Power Sources, 342, 546-552 (2017).

42. Prasad, K. P.; Chen, Y.; Chen, P., ACS Appl. Mater. Interfaces, 6 (5), 3387-3393 (2014).

43. Wang, F.; Liu, P.; Nie, T.; Wei, H.; Cui, Z., Int. J. Mol. Sci., 14 (1), 17-29 (2013).

44. Seselj, N.; Engelbrekt, C.; Ding, Y.; Hjuler, H. A.; Ulstrup, J.; Zhang, J., Adv. Energy Mater., 8 (13), 1702609 (2018).

45. Dong, X.; Xing, G.; Chan-Park, M. B.; Shi, W.; Xiao, N.; Wang, J.; Yan, Q.; Sum, T. C.; Huang, W.; Chen, P., Carbon, 49 (15), 5071-5078 (2011). 
46. Liu, H.; Kuila, T.; Kim, N. H.; Ku, B.-C.; Lee, J. H., J. Mater. Chem. A, 1 (11), 3739-3746 (2013).

47. Prodromidis, M. I.; Florou, A. B.; Tzouwara-Karayanni, S. M.; Karayannis, M. I., Electroanalysis, 12 (18), 1498-1501 (2000).

48. Zeng, T.; Leimkühler, S.; Koetz, J.; Wollenberger, U., ACS Appl. Mater. Inter., 7 (38), 21487-21494 (2015).

49. Jensen, P. S.; Chi, Q.; Grumsen, F. B.; Abad, J. M.; Horsewell, A.; Schiffrin, D. J.; Ulstrup, J., J. Phys. Chem. C, 111 (16), 6124-6132 (2007).

50. Blonder, R.; Katz, E.; Willner, I.; Wray, V.; Bückmann, A. F., J. Am. Chem. Soc., 119 (49), 11747-11757 (1997).

51. Liu, D.; Liu, H.; Hu, N., Electrochim. Acta, 55 (22), 6426-6432 (2010).

52. Xiao, X.; Ulstrup, J.; Li, H.; Wang, M. e.; Zhang, J.; Si, P., Electrochim. Acta, 130, 559-567 (2014).

53. Xiao, X.; Conghaile, P. Ó.; Leech, D.; Magner, E., ChemElectroChem, 6 (5), 1344-1349 (2019).

54. Xiao, X.; Wang, M. e.; Li, H.; Pan, Y.; Si, P., Talanta, 125, 366-371 (2014).

55. Xu, Q.; Gu, S.-X.; Jin, L.; Zhou, Y.-e.; Yang, Z.; Wang, W.; Hu, X., Sensor. Actuat. B-Chem., 190, 562569 (2014).

56. Foulds, N. C.; Lowe, C. R., J. Chem. Soc. Faraday Trans., 82 (4), 1259-1264 (1986).

57. Moore, C. M.; Akers, N. L.; Hill, A. D.; Johnson, Z. C.; Minteer, S. D., Biomacromolecules, 5 (4), 12411247 (2004).

58. Akers, N. L.; Moore, C. M.; Minteer, S. D., Electrochim. Acta, 50 (12), 2521-2525 (2005).

59. De Santis, G.; Fabbrizzi, L.; Licchelli, M.; Pallavicini, P., Inorg. Chim. Acta, 225 (1), 239-244 (1994).

60. Reuillard, B.; Le Goff, A.; Agnès, C.; Holzinger, M.; Zebda, A.; Gondran, C.; Elouarzaki, K.; Cosnier, S., Phys. Chem. Chem. Phys., 15 (14), $4892-4896$ (2013).

61. Wilson, R.; Turner, A. P. F., Biosens. Bioelectron., 7 (3), 165-185 (1992).

62. Fortier, G.; Vaillancourt, M.; Bélanger, D., Electroanalysis, 4 (3), 275-283 (1992). 